\title{
Supplemental Light Quality Affects Budbreak, Yield, and Vase Life of Cut Roses
}

\author{
G.L. Roberts, M.J. Tsujita, and B. Dansereau' \\ Department of Horticultural Science, University of Guelph, Guelph, Ont. NIG \\ 2W1, Canada
}

\author{
Additional index words. far-red light, metal halide, high-pressure sodium, supplemental \\ lighting, Rosa $\times$ hybrida
}

\begin{abstract}
Rosa xhybrida 'Samantha' plants were grown under high-pressure sodium (HPS) lamps, HPS lamps fitted with blue gel filters to reduce the red to far-red (R:FR) ratio, or metal halide lamps. $R$ : FR ratios were 1:0.95, 1:2, and 1:0.26 for HPS; filtered HPS, and metal halide, respectively. Although the R : FR ratio for metal halide was 3.5 times higher than for HPS, the total energy from 630 to $750 \mathrm{~nm}$ was 2.8 times lower. At a nighttime supplemental photosynthetic photon flux of 70 to $75 \mu \mathrm{mol} \cdot \mathrm{m}^{-2} \cdot \mathrm{s}^{-1}$, plants under HPS and metal halide lamps produced $49 \%$ and $64 \%$ more flowering shoots, respectively, than those under filtered HPS (averaged over two crop cycles). The quality index for flowers under HPS, metal halide, and filtered HPS was 25.0,23.3, and 18.5, respectively. Vase life was 10 to 11 days, regardless of treatment.
\end{abstract}

Supplementary irradiation with high-pressure sodium lamps (HPS) to increase rose yield is a generally accepted practice in northern climates of North America and Europe. Tsujita (1982) suggested that the high red to far-red (R: FR) ratio of light radiated by HPS lamps is responsible for increased budbreak and subsequent yield. Research has shown that red light effectively inhibits flowering and promotes lateral branching in chrysanthemum [Dendranthema grandiflorum (Ramat.) Kitamura] (Heins and Wilkins, 1979). Mortensen and Stromme (1987) demonstrated that light with a high $\mathrm{R}$ : FR ratio stimulated lateral break formation while reducing plant height in chrysanthemum and tomato (Lycopersicon esculentum Mill.). Earlier studies showed that far-red light will suppress side shoot growth in tomatoes when applied immediately after a 16-h photoperiod (Tucker, 1975)

Plastic films and fluid-filled filters have been used to change the quality of light provided to plants. In general, blue filters alter the $\mathrm{R}$ : FR portion of the spectrum (630 to 750 rim). Panels filled with copper sulfate solution absorb the far-red portion, while blue plastic filters absorb the red portion (McMahon, 1991 ). An added benefit of the copper sulfate solution filter is that it absorbs much of the heat produced by the light source.

Received for publication 19 June 1992. Accepted for publication 9 Jan. 1993. Roses donated by Jackson and Perkins Roses, Ore. Hydrokorrel media donated by Dekker Greenhouse, Ont. Financial support was provided by GTE Sylvania, the Natural Sciences and Engineering Resource Council of Canada, and Agriculture Canada. Reference to trade names does not imply recommendation to the exclusion of others that may be suitable. The cost of publishing this paper was defrayed in part by the payment of page charges. Under postal regulations, this paper therefore must be hereby marked advertisement solely to indicate this fact.

'Laval Univ., Qué. G1 K 7P4, Canada.
The objective of this study was to determine if the high $\mathrm{R}$ : FR ratio inherent in HPS lamps is responsible for increased budbreak and yield in roses.

One hundred and eight 'Samantha' 3X commercial-grade rose plants were potted in 4- to 8-mm Hydrokorrel expanded clay medium (Jongkindb V. Hydro, Aalsmeer, Holland). Twenty -liter plastic pots with side drainage holes $2 \mathrm{~cm}$ from the bottom were used to allow for a reservoir of nutrient solution to be used by the plants between irrigations. Plants were pruned to a uniform height of $\approx 40 \mathrm{~cm}$ and spaced in double rows, pot to pot, in groups of 12 on a recirculating hydroponic system. Plants were irrigated for 1 min every $90 \mathrm{~min}$ (24-h basis) with a nutrient solution (Sonneveld and

Fig. 1. Spectral outputs of a 400-W high-pressure sodium (HPS) lamp, a 400-W HPS lamp fitted with a blue plastic filter, and a $400-\mathrm{W}$ metal halide lamp at a photosynthetic photon flux of 70 to $75 \mu \mathrm{mol} \cdot \mathrm{m}^{-2} \cdot \mathrm{s}^{-1}$. the ratio determined.

The experiment was a completely randomized design with three treatments, three replications of each treatment, and 12 plants per replication, and was run for two crop cycles from 12 Nov. to 25 Dec. 1991 and 7 Jan. to 21 Feb. 1992. Data were subjected to analysis of variance and Student-Newmans-Keuls tests.

At harvest, the number of breaks per plant for each illumination treatment per crop cycle was noted and separated into three shoot classes: flowering, blind, and dormant [dormant shoots included those that broke but elongated $<1 \mathrm{~cm}$ and those that did not break (Van den Berg, 1987)]. Stem length (from tip of flower to cut end), stem weight, and yield of flowers per plant were recorded immediately

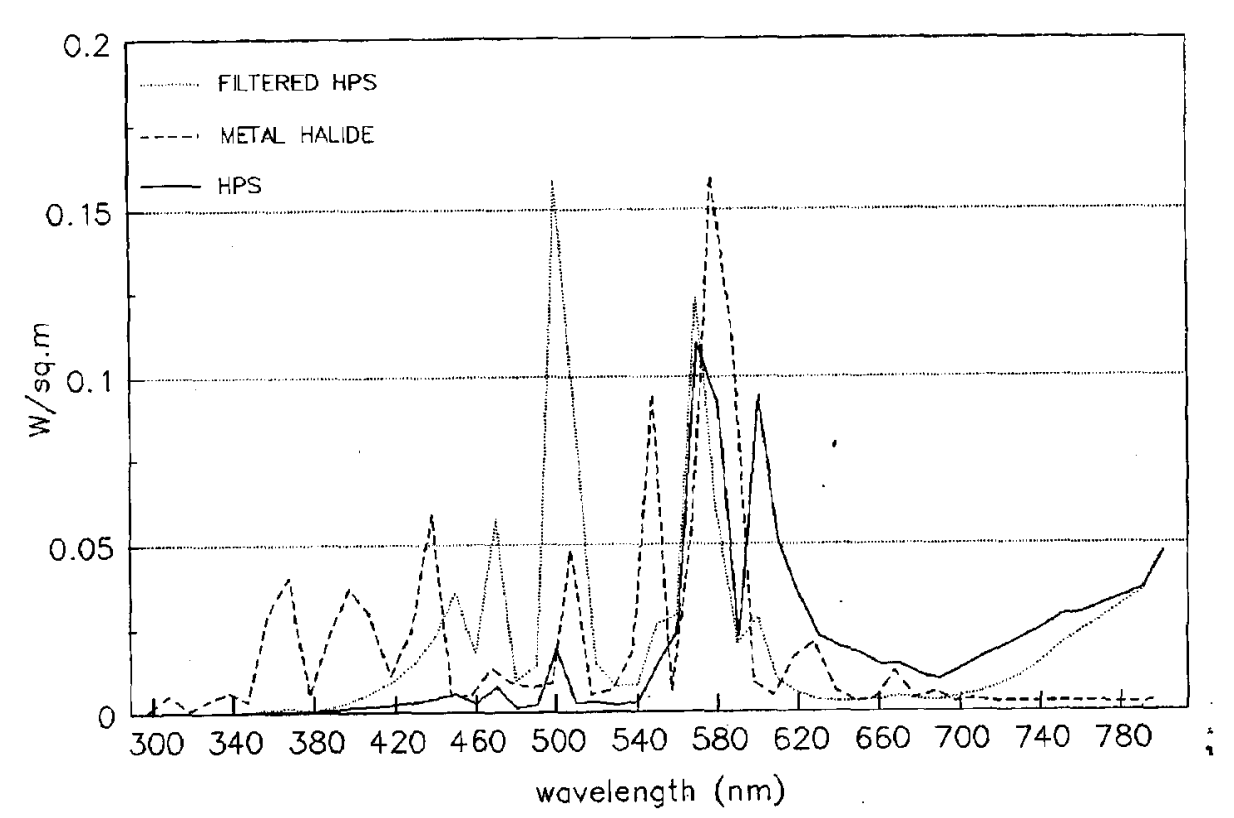

Straver, 1989) maintained at an electrical conductivity of $2.5 \mathrm{dS} \cdot \mathrm{m}^{-1}$ and a $\mathrm{pH}$ of 5.5 to 6.0 . Greenhouse temperatures were maintained at $18 \mathrm{C}$ at night and $24 \mathrm{C}$ during the day.

Treatments were as follows: 1) 400-W HPS lamps (model LU400; Sylvania, Toronto, Ont.) fitted with no. 141 Bright Blue gel filters (Lee Filters; Score Systems, Ont., Canada) to reduce the R : FR ratio; 2) HPS lamps fitted with no. 2110.9 -neutral-density filters (Lee Filters) to reduce photosynthetic photon flux (PPF); and 3) metal halide lamps (Sylvania M400). Filters were replaced at the beginning of each crop cycle. The nine lamps were suspended individually over the nine plots so that supplemental PPF levels were 70 to 75 $\mu \mathrm{mol} \cdot \mathrm{m}^{-2} \cdot \mathrm{s}^{-1}$ at $1 \mathrm{~m}$ above the surface of the pots at night (Tsujita, 1982). The lamps were raised as the crop grew to maintain the PPF in this range at the top of the canopy at all times. The spectral output of the lamps was determined at night using a portable spectro-radiometer (model LI-1800; LI-COR, Lincoln, Neb.) placed on the floor $(150 \mathrm{~cm}$ below the lamp). The area under the curves from 630 to $700 \mathrm{~nm}$ (broad-band red) and from 700 to 750 urn (broad-band far-red) was calculated and 
after harvest. From these data, a quality index (QI) (yield $\times$ weight/length) was calculated (White and Richter, 1973).

Flower quality and vase life. Harvested roses were placed in water obtained by reverse osmosis immediately after being cut and hydrated at $4 \mathrm{C}$ for $24 \mathrm{~h}$. Twenty flowers (collected overall replications) were used from each treatment. Stems were cut to a uniform length of $45 \mathrm{~cm}$ (measured from the tip of the flower) and stripped of leaves except for the one three-leaflet leaf nearest the flower. Each stem was placed in a 250 -ml graduated cylinder containing $250 \mathrm{ml}$ deionized water and placed in a room at $20 \mathrm{C}$ with $14 \mu \mathrm{mol} \cdot \mathrm{m}^{-2} \cdot \mathrm{s}^{-1}$ light measured at the bench top. Flower life was considered over when blooms developed bent neck, bluing, or petal wilt. Flowering stems were arranged in a completely randomized design; each stem was one replication. Data were subjected to analysis of variance.

Spectral graphs of the various light treatments showed R: FR ratios of 1:0.95 for HPS, 1:2 for filtered HPS, and 1:0.26 for metal halide (Fig. 1). Although the R : FR ratio of metal halide is 3.5 times that of HPS, the actual energy in this range is 2.8 times lower.

Plants under HPS and metal halide produced $71 \%$ and $85 \%$ more flowers, respectively, than plants under filtered HPS (Table 1). Results were similar in cycle 2 (Table 1 ): HPS and metal halide produced $27 \%$ and $43 \%$ more flowers, respectively, than filtered HPS. The number of dormant buds per plant under HPS was similar to that under filtered HPS in both cycles, but there was $60 \%$ less dormant shoots under metal halide lamps in cycle 2 . Blind shoot production was inconsistent. In cycle 1 , there was about one more blind shoot per plant under HPS than filtered HPS; but, in cycle 2 , results for all treatments were similar.

Flower QI varied among treatments (Table 2). The highest QI was under HPS and the lowest was under filtered HPS. Plants under metal halide produced intermediate-quality stems. Although QI differences were statistically different, the differences may not be economically important to producers, since the flowers were similar visually. Stems were $11 \%$ longer on plants under filtered HPS than on those under HPS (Table 2). Fresh weight of stems from plants under filtered HPS and metal halide was $20 \%$ higher than that of stems from plants under HPS (Table 2). The average vase life of flowers from all treatments was 10.5 days, and the $\mathrm{F}$ test showed no significant difference among treatments.

The consistently higher proportion of flowering shoots under HPS and metal halide suggests that the high R: FR ratios of 1:0.95 and 1:0.26 for these imps increased flower production. Since the production of blind shoots was inconsistent over the cycles (Table 1), there does not seem to be a relationship between light Source or quality and blind shoot production. In all cases, most dormant buds were below the canopy, where light levels

Table 1. Influence of lights with varying red to far-red (R: FR) ratios on the production of flowering, blind, and dormant shoots in Rosa xhybrida 'Samantha'. Cycle 1 was 12 Nov. to 25 Dec. 1991. Cycle 2 was 7 Jan. to 21 Feb. 1992.

\begin{tabular}{|c|c|c|c|c|c|c|}
\hline \multirow[b]{3}{*}{$\begin{array}{l}\text { Shoot } \\
\text { type }\end{array}$} & \multicolumn{6}{|c|}{ Light treatment } \\
\hline & \multicolumn{2}{|c|}{$\begin{array}{l}\text { Filtered HPS } \\
(\mathrm{R}: \quad \mathrm{FR}=1: 2)\end{array}$} & \multicolumn{2}{|c|}{$(\mathrm{R}: \mathrm{FR}=1: 0.95)$} & \multicolumn{2}{|c|}{$\begin{array}{c}\text { Metal halide } \\
(\mathrm{R}: \mathrm{FR}=1: 0.26)\end{array}$} \\
\hline & $\begin{array}{c}\text { Percent } \\
\text { potential }\end{array}$ & $\begin{array}{c}\text { Shoots/ } \\
\text { plant }\end{array}$ & $\begin{array}{r}\text { Percent } \\
\text { potential } \\
\end{array}$ & $\begin{array}{c}\text { Shoots/ } \\
\text { plant }\end{array}$ & $\begin{array}{r}\text { Percent } \\
\text { potential } \\
\end{array}$ & $\begin{array}{c}\text { Shoots/ } \\
\text { plant }\end{array}$ \\
\hline \multicolumn{7}{|c|}{ Cycle 1} \\
\hline Dormant & $55^{*}$ & 3 & 38 & 2.6 & 42 & 2.7 \\
\hline Flowers & 26 & $1.4^{*}$ & 36 & 2.4 & 42 & 2.6 \\
\hline Blinds & 19 & 1.0 & $26^{*}$ & $1.8^{*}$ & 16 & 1.1 \\
\hline Total breaks & --- & 2.4 & --- & 4.2 & --- & 3.7 \\
\hline Potential breaks & --- & 5.4 & --- & 6.8 & --- & 6.4 \\
\hline \multicolumn{7}{|c|}{ Cycle 2} \\
\hline Dormant & 30 & 2.0 & 30 & 2.3 & $16^{*}$ & $1.1^{*}$ \\
\hline Flowers & $47^{*}$ & $3.0^{*}$ & $53 *$ & 3.8 & $60 *$ & 4.3 \\
\hline Blinds & 23 & 1.5 & 17 & 1.3 & 24 & 1.8 \\
\hline Total breaks & --- & 4.5 & --- & 5.1 & & 6.1 \\
\hline Potential breaks & --- & 6.7 & --- & 7.4 & --- & 7.3 \\
\hline
\end{tabular}

${ }^{2}$ High-pressure sodium.

'Potential is the total of dormant plus flowering plus blind shoots per 12 plants.

*Significant at $P=0.05$ by Student-Newman-Keuls test.

Table 2. Quality index $(\mathrm{QI})$ (yield $\times$ weight/stem length), stem length, and fresh weight of rose stems grown under various red to far-red $(\mathrm{R}: \mathrm{FR})$ light ratios.

\begin{tabular}{lccc}
\hline $\begin{array}{l}\text { Light } \\
\text { treatment }\end{array}$ & QI & $\begin{array}{c}\text { Stem length } \\
(\mathrm{cm})\end{array}$ & $\begin{array}{c}\text { Stem fresh } \\
\text { wt }(\mathrm{g})\end{array}$ \\
\hline $\begin{array}{l}\text { High-pressure sodium } \\
\quad \text { R: FR = 1:0.95) }\end{array}$ & $25.0 \mathrm{a}^{2}$ & $53.8 \mathrm{~b}$ & $25.5 \mathrm{~b}$ \\
$\begin{array}{l}\text { Filtered high-pressure sodium } \\
\quad \text { R: FR=1:2) }\end{array}$ & $18.5 \mathrm{C}$ & $60.0 \mathrm{a}$ & $29.7 \mathrm{a}$ \\
$\begin{array}{l}\text { Metal halide } \\
\quad \text { (R: FR= 1:0.26) }\end{array}$ & $23.3 \mathrm{~b}$ & $56.1 \mathrm{ab}$ & $30.6 \mathrm{a}$ \\
\hline
\end{tabular}

${ }^{2}$ Mean separation in columns at $P 0.05$ by Student-Newman-Keuls test.

were low and much of the red light was filtered out by leaves. It is unlikely that inhibitory effects of the blue-green light (400 to $540 \mathrm{~nm}$ ) (Fig. 1) decreased yield, because metal halide also has a high amount of light in the bluegreen range of the spectrum (Fig. 1) compared to HPS. The increase in ambient light levels to 300 to $400 \mu \mathrm{mol} \cdot \mathrm{m}^{-2} \cdot \mathrm{s}^{-1}$ toward the end of the experiment probably began to mask the effect of supplemental lighting.

The high R: FR ratio of light in HPS lamps seems to affect the number of buds that break substantially. We think that the process may be phytochrome-mediated, with the high $\mathrm{R}$ : FR ratio influencing the phytochrome photoequilibrium $\left(\mathrm{P}_{\mathrm{fr}}\right.$, relative to $\mathrm{P}_{\text {total }}$ or $\left.\emptyset\right)$, since research has shown that a high $\varnothing$ promotes lateral branching in other plants such as chrysanthemum and tomato (McMahon et al., 199 1; Mortensen and Stromme, 1987). Further studies on the reversibility of the response are needed to substantiate our suggestion.

Future studies also need to consider increasing the R: FR ratio of light under the plant canopy to increase the number of breaks in this space.

\section{Literature Cited}

Heins, R.D. and H.F. Wilkins. 1979. The influence of node number, light source, and time of irra- diation during darkness on lateral branching and cutting production in 'Bright Golden Anne' chrysanthemum. J. Amer. Soc. Hort. Sci. 104:265-270.

McMahon, M.J., J.W. Kelly, D.R. Decoteau, R.E. Young, and R.K. Pollock. 1991. Growth of Dendranthema $\times$ grandiflorum (Ramat.) Kitamura under various spectral filters. J. Amer. Soc. Hort. Sci. 116:950-954.

Mortensen, L.M. and E. Stromme. 1987. Effects of light quality on some greenhouse crops. Scientia Hort. 33:27-36.

Sonneveld, C. and N. Straver. 1989. Nutrient solutions for vegetables and flowers grown in water and substrates. Consulent-schap. voor de Tuinbouw. Serie: Voedingsoplossingen glastuinbouw. 8 .

Tsujita, M.J. 1982. Flower cutting practices for greenhouse roses receiving supplemental irradiation. HortScience 17:44-45.

Tucker, D.J. 1975. Far-red light as a suppressor of side shoot growth in the tomato. Plant Sci. Lett. 5:127-130.

Van den Berg, G.A. 1987. Influence of temperature on bud break, shoot growth, flower bud atrophy and winter production of glasshouse roses. Landbouwuniversiteit te Wageningen, Centrale Offsetdrukkerij [PUDOC).

White, J.W. and D. Richter. 1973. Supplementary fluorescent lighting and low moisture stress improve growth of greenhouse roses. J. Amer. Soc. Hort. Sci. 98:605-607. 